\title{
Effect of an educative intervention on the clinical ability of physicians in the risk factor identification of metabolic syndrome
}

\author{
Carlos E. Cabrera-Pivaral ${ }^{1,2^{\star}}$, Bellaney G. Hobert-Cepeda ${ }^{1,3}$, Astrid L. Berdugo-Rodriguez $^{3}$ \\ ${ }^{1}$ Unidad de Investigación en Epidemiología Clínica, Hospital de Especialidades, Centro Médico Nacional de Occidente, Instituto \\ Mexicano del Seguro Social, Guadalajara, México; ${ }^{*}$ Corresponding Author: carlos.cabrera@imss.gob.mx \\ ${ }^{2}$ Centro de Investigación en Salud, Departamento de Ciencias Sociales, Departamento de Salud Pública; Centro Universitario de \\ Ciencias de la Salud, Universidad de Guadalajara, Guadalajara, México; \\ ${ }^{3}$ Universidad Autónoma de Guadalajara, Guadalajara, México.
}

Received 14 May 2011; revised 27 June; accepted 29 August 2011.

\begin{abstract}
Aim: To measure the effect of an educative intervention on the clinical ability of family physicians of two First Contact Units, (UMF, IMSS) from the metropolitan area of Guadalajara, in the Risk Factor Identification of metabolic syndrome. Methodology: A quasi-experimental study was carried out with a control group using basal and final measurements. The educative intervention of the experimental group included one in-theclassroom work and another at the consulting room. Instrument was validated by a panel of experts and consisted of 40 questions of five cases presenting problems, reaching a reliability index of $\mathbf{0 . 8 4}$. Results: There was no significant difference at base measurement among the different levels of clinical ability among groups $(p=0.82)$. At the end of the follow-up, a significant increase in the experimental group (29 with 20 - 23 vs. 29 with 24 - 33 in the control group) was observed. Conclusions: The advantage observed at the different levels of the experimental group reflects the impact of the alternative educative program which needs to be a programmatic guide for future educative interventions for health workers seeking to transform their own clinical practice.
\end{abstract}

Keywords: Clinical Ability; Metabolic Syndrome; Educative Intervention

\section{INTRODUCTION}

In Mexico, the prevalence of MS among the adult population is higher than in Caucasian populations [1,2]; more than 6 million Mexicans are affected if the criteria of the World Health Organization (WHO) is applied, and more than 14 million if the criteria of the third adult treatment panel (ATP III) of The National Cholesterol Education Program (NCEP) is applied [3].

On the other hand, it has been shown that weight loss is the only intervention that improves all risk factors observed in MS patients. This is a clear sign of the necessity to implement preventative measures as well as prompt attention to MS.

This syndrome requires prompt identification and clinical management by the first contact physician. This management ability permits the physician to recognize risk factors, which in the end would be reflected by a reduced risk for diabetes mellitus type 2 and cardiovascular disease for patients.

The education of health personal on Risk Factors Identification (RFI) requires an adequate means to assess the scope and limitations of clinical ability achieved during formation and its own professional practice. Assessment of physicians has traditionally been made in a stereotyped manner, memory-oriented, and much of the time centered on questions unrelated to clinical practice. It is occasionally carried out with clinical cases almost always obtained from a book and with multiple choice answers [11].

Being able to assess the ability and competence of physicians in solving clinical problems that they may face has always been a major concern for educators [7-9].

Clinical competence and ability is defined as the performance of the physician in problematic clinical situations. A competent medical practitioner is one who possesses the necessary skills, knowledge and attitudes, and able to synthesize these attributes by a complex set of behaviors to deliver high-quality medical care [10].

The aim of the study was to measure the effect of an educative intervention on the clinical ability of family 
physicians (FP) of two First Contact Units, (FCU) at the Instituto Mexicano del Seguro Social (IMSS), in the RFI of MS [12].

\section{MATERIALS AND METHODOLOGY}

This is a quasi-experimental study with a control group using base and final measurements. It was carried out on FP of First Contact Unit (FCU) A and B at the Instituto Mexicano del Seguro Social, Jalisco Delegation, during the period from January to October 2008.

\subsection{Sample}

We performed a non-aleatory selection of two FCUs from the 23 units in the area of Guadalajara. Among other characteristics of these units are the following: both units provided patients diagnosed with MS, and are similar in terms of the number of consulting and support services (laboratory, X-ray, etc.). All family physicians at the FCU who met the criteria were invited to participate in the educative intervention.

\subsection{Variables}

Independent: Participative educative intervention in the experimental group. Intervener: Time of professional activity as family medicine specialist. Dependents: Clinical ability. Risk Factor Identification is defined as the competency which enables the family physician, in the face of a problematic case, to confront difficult situations of clinical experience of variable complexity.

\subsection{Study Stages}

1) Development and validation of an instrument to assess the clinical ability of family physicians in the management of the patient with MS. An instrument to explore the grade of competence and clinical ability was constructed; it measures the family physician's ability to carry out interpretations, judgments and proposals in the face of four real clinical cases theoretically made up of patients. The instrument was subjected to a panel of 5 experts, that is, 3 endocrinology specialists and 2 internal medicine specialists dedicated to clinical practice for a minimum of 2 years, who conferred to the instrument a validity of concept, contents and criteria.

The instrument is made up of 40 questions spread over indicator: identification of risk factors. Taking into account the experts' observations, 20 questions with true correct answers and 20 with false correct answers, a glossary of terms was created with the precise meanings of the terms utilized in the questions. The instrument reliability had a Kuder-Richardson coefficient of 0.84 .
$[13,14]$

2) Development and validation of contents, criteria and management standards for the MS patient. A study guideline that includes explicit criteria and standards in algorithmic form was created for diagnosis and treatment. Construction of the algorithm was carried out based on available scientific literature and was validated through a consensus of experts. [14-16]

3) Implementation of experimental educative strategy. The range of the educative strategy is based on the participative focus of students through communication; utilizing dialog, exchange of ideas, and sharing mutual actions in the diagnosis and treatment of MS patients. The duration of the intervention was 6 months: 5 hours a week ( 2 weekly sessions of 1.5 hours in the consulting room, and 2 hours in the classroom). This was developed in the following manner: [7]

1) Classroom activities: Based on a previously selected program of subjects and readings, during the classroom sessions the following types of activities were carried out:

- Theoretical subject presentation by teacher (40 minutes)

- Discussion in small groups: students discussed the subject presented one session before, including analytical revision of literature. Each group analyzed points of agreement and disagreement (30 minutes).

- Debate: after the small-group discussion exercise, students presented to the entire group a condensed version of their ideas, comments, discrepancies and arguments, which they contrasted with other versions (30 min).

- Review of clinical cases. Physicians presented a clinical case in a rotary manner allowing for everyone to have the opportunity to participate.

- Commented critical review of the literature, discussion and analysis of clinical cases.

2) Activities at the medical consulting room: The whole purpose is to provide care to patients with MS to strengthen the risk factor identification. The consultations were carried out by the group of instructors, ensuring participation of all physicians included in the study.

Diverse scientific texts and articles were reviewed for the construction of theoretical contents and pedagogical materials. The strategy was developed by one physician specialized in Internal Medicine holding a Master's degree in Public Health Sciences, one physician specialized in Family Medicine holding a Master's degree in Medical Sciences, one physician specialized in Nutrition holding a Master's degree in Education, and two general physicians with Master's degrees in Nutrition; all experienced in investigation projects. 


\subsection{Statistical Analysis}

In the case of dimensional variables, data is shown as a \pm average standard deviation (SD), or mean $(25 \%-75 \%$ percentile), according to parametrical or non-parametrical distribution respectively. Nominal variables are shown as numbers or percentages. Comparisons between groups with and without educative intervention were established through square chi in the case of nominal or categorical variables; for quantitative variables, through the Mann-Whitney U-test for two independent samples. For calculating explainable scores by random effect, the Perez-Padilla and Viniegra Formula were utilized [12]. For changes in medical ability, the Wilcoxon rank test (before-after) was utilized. A value of $p<0.05$ was considered to be significant; however, it is preferable to express exact numbers. For data analysis the SPSS statisticcal package for Windows, version 10.0, was utilized.

\section{RESULTS}

\subsection{Clinical Ability}

40 primary-care physicians willing to participate were included, 21 from FCU (A) who received educative intervention, and 19 from FCU (B) who corresponded to the control group.

Table 1 shows socio-demographic characteristics of the total sample. Age averages were similar in both groups, $43 \pm 8$ vs. $44 \pm 6$ years respectively $(\mathrm{p}=0.85)$. There was no significant difference in gender distribution between groups $(p=0.94) .86 \%$ of physiccians in the experimental group have a specialty, vs. $78 \%$ in the control group, this being a non-significant difference $(p=0.73)$. There were no significant differences between work category and seniority within IMSS ( $p=$ 0.53 and 0.34 , respectively).

The clinical ability Risk factor identification level obtained for each group is shown in Table 2; the base global measurement score for the control group was 27 with a range of 7 to 27 , and 26 for the experimental group with a range of 7 to 32 ; it is observed that no significant difference was found during base measurement between the different levels of clinical ability among groups $(p=0.84)$; both the experimental and control groups have a higher frequency of regular level $(33.3 \%$ vs. $36.8 \%$, respectively). At the end of follow-up a significant increase of $9.5 \%$ was observed in the experimental group of physicians obtaining a high ability level; whereas in the control group no physician reached that grade. The proportion of physicians with a regular ability level increased in the experimental group (from $33.3 \%$ to $52.4 \%$ at the end of follow-up), whereas in the control group it decreased from $36.8 \%$ to $31.6 \%$, thus increasing proportion of low level physicians from $26.3 \%$ to $47.4 \%$.

\subsection{Comparison of Mean Scores Obtained by Indicators}

Indicator-obtained differences for each group are shown in Table 2. During base measurement, the indicators for identification of risk factors result showed no

Table 1. Comparison of socio-demographic characteristics of family physicians between groups (N 40).

\begin{tabular}{|c|c|c|c|}
\hline Variable & FCU (A) Educative Intervention (N 21) & FCU (B) Without Educative Intervention (N 19) & p value \\
\hline Age (years) & $43 \pm 8$ & $44 \pm 6$ & 0.81 \\
\hline \multicolumn{4}{|l|}{ Gender, $N$ : } \\
\hline Female & $9(43 \%)$ & $8(42 \%)$ & \\
\hline Specialization, N & $18(86 \%)$ & $14(78 \%)$ & 0.74 \\
\hline \multicolumn{4}{|l|}{ Labor category, $\mathrm{N}$} \\
\hline Permanent & $16(76 \%)$ & $16(84 \%)$ & 0.52 \\
\hline Temporary & $5(24 \%)$ & $3(16 \%)$ & \\
\hline Seniority & $12 \pm 7$ & $14 \pm 7$ & 0.32 \\
\hline
\end{tabular}

Table 2. Comparison of clinical ability level by scores obtained from a control group and an experimental group of physicians.

\begin{tabular}{|c|c|c|c|c|}
\hline \multirow{2}{*}{ Risk factor identification Level (Score) } & \multicolumn{2}{|c|}{ Experimental group } & \multicolumn{2}{|c|}{ Control group } \\
\hline & Basal $^{*}$ & Final $^{* *}$ & Basal & Final \\
\hline Global (Median/Range) & $26(7-32)$ & $29(20-33)^{*}$ & $27(7-27)$ & $27(12-26)$ \\
\hline High (33-40) & $0(0 \%)$ & $3(14.3 \%)^{\dagger * *}$ & $0(0 \%)$ & $0(0 \%)$ \\
\hline Regular (25-32) & $7(33.3 \%)$ & $11(52.4 \%)^{\dagger * *}$ & $7(36.8 \%)$ & $6(31.6 \%)$ \\
\hline Low $(17-24)$ & $5(23.8 \%)$ & $7(33.3 \%)^{\dagger * *}$ & $5(26.3 \%)$ & $9(47.4 \%)$ \\
\hline Very low (9-16) & $6(28.6 \%)$ & $0(0 \%)^{\dagger * *}$ & $6(31.6 \%)$ & $4(21.1 \%)$ \\
\hline Explainable by random effect $<8$ & $3(14.3 \%)$ & $0(0 \%)^{\dagger}$ & $1(5.3 \%)$ & $0(0 \%)$ \\
\hline
\end{tabular}

${ }^{\dagger} \mathrm{p}<0.05$ vs. base of same group; ${ }^{* *} \mathrm{p}<0.05$ vs. control group in same evaluation; ${ }^{*} \mathrm{p} \leq 0.05$ vs. base of same group. 
significant difference among groups.

At the end of the intervention, the experimental group had increased indicators in the identification of risk factors. For the control group, none of the indicators showed statistically significant differences when relating initial and final measurements.

\section{DISCUSSION}

With regard to the educative process, it is acknowledged that both groups at the beginning of the educative intervention showed a homogeneous distribution in relation to competence levels of clinical ability; after the educative intervention in the control group, a downward displacement was observed without presenting any cases explainable by chance, where the control group showed no modifications concerning the levels of product study variables of informative rote learning, characterized within traditional teaching-learning models [7].

In the experimental group, an upward displacement was observed in competence levels of clinical ability concerning decision making in patient management. It is important to recognize that only one physician is at a very low level and/or random and that there exists a $30 \%$ increase in regular level and the appearance of two physicians in the high level $[17,18]$.

While the communicative-participative strategy which was offered to the family physicians in the experimental group was marked by reflection-action over the interpretation of risk factors, similar data to those reported by Gonzalez C.A. [3], measuring the effect of an educative intervention within critical readings of investigation reports.

This educative strategy, an alternative to the traditional model, allows the advancement of family physiccians at different levels, because educative methodology fosters physicians' participation in the construction of their own knowledge generated by confronting difficult, real clinical cases.

The advantage observed at the different levels of the experimental group reflects the impact of the alternative educative program which needs to be a programmatic guide for future educative interventions for health workers seeking to transform their own clinical practice without forgetting that, to influence behavioral change in patients with MS, the cultural sphere where it is developed should be considered.

Of upmost importance is the proposal to modify the educative processes concerning the formation of human resources as well as the continuous education to transfer the clinical practice to higher levels of ability; this demands the adequate living reality as the first level of attention with the objective of delivering integral services.
The utilization of human behavior measurement instruments along with clinical practice have become more and more useful to assess the processes of human resources formation and service delivery. These kinds of instruments aim to discriminate dominance over one particular issue, namely, competence of clinical ability, which demands a level of reliability within its construction to avoid information biases; characteristics which this study covers and which allows control of said biases together with discrimination of the diverse levels of clinical ability. It must be recognized, however, that this system does not allow identification of qualitative variables that could be generating a favorable difference which is assumed to be controlled through homogenization of groups $[19,20]$.

The alternative educative model used led to the involvement of family physicians through recognition of the creation of their own knowledge in a mainstream manner and which unchained and directed refined proposals in the clinical practice of MS measured by selfcriticism.

It is acknowledged that the experimental group was formed by family physicians, the majority of whom were specialized in family medicine, and that this could have an impact on the educative strategy in the levels of clinical ability; before the intervention, however, such levels were homogeneous, which reflects the initial control for these variables, thus all improvements in the experimental group were due to the effect of educative intervention and not to a probable confusion variable.

The participation of the experimental group leader was due to the learning commitment in the reflectionaction mode, and who was responsible for developing strategies to promote the family physicians' participation with the aim of building their own knowledge from reflection-action patterns which were lacking in the control group.

Finally, the utilization of educative investigation as a learning tool (which allows feedback of educative process) allows consolidation of educative strategies which directs family physicians' participation within formative schemes for their clinical practice, which contribute to the development of competence concerning clinical ability in its different levels, and it can be applied not only in the matter of a patient with metabolic syndrome but in any other condition which requires the physician's clinical ability to reach an accurate diagnosis and timely treatment.

Because the prevalence of MS in Mexico is high as in other countries; as well as the cardiovascular and metabolic consequences of this syndrome, that can be generated by the lack of an early diagnosis and timely treatment, it is recommended that the first contact physicians 
be trained regularly through such educational strategies with the aim of providing the most appropriated tools for increasing their clinical competence as reflected in a better decision making in benefit of their patients.

\section{REFERENCES}

[1] Lerman, G.I., Aguilar-Salinas, C.A., Gómez-Pérez, F.J., Reza, A. A., Hernández, J. S. (2004) El síndrome metabólico, posición de la Sociedad Mexicana de nutrición y endocrinología, sobre la definición, fisiopatología y diagnóstico. Características del síndrome metabólico en México. Revista de Endocrinología y Nutrición, 12, 109-122.

[2] Luquez, H., De Loredo, L., Madoery, R.J. (2005) Síndrome Metabólico: prevalencia en dos comunidades de Cordóba Argentina de acuerdo con definiciones de ATP III y OMS. Revista de la Federacion Argentina de Cardiologia, 43, 80-95.

[3] Rodríguez, P.A., Sánchez, L.M., Martínez, V.L. (2002) Síndrome metabólico. Rev Cub Endocrinol, 13, 238-252.

[4] Dekker, J. M., Girmain, C., Rhodes, T., Nipjels, G. (2005) Metabolic Síndrome and 10 year cardiovascular disease risk in the Hoorn study. Circulation, 112, 666-673.

[5] Gutiérrez, G.S.N., Aguilar, M.E., Viniegra, V.L. (2001) Validación de un instrumento para evaluar la competencia clínica del médico familiar. Revista Medica del Instituto Mexicano del Seguro Social, 37, 201-210.

[6] Chávez, V., Aguilar, M. (2002) Aptitud clínica en el manejo de la familia, en residentes de Medicina Familiar. Revista Medica del Instituto Mexicano del Seguro Social, 40, 477-481.

[7] Burr, W.A. (2004) Diabetes UK. Diabetic Medicine, 21, $1-16$

[8] Viniegra, V.L., Pérez-Padilla, J.L., (1991) JR. El desafío de la evaluación de la competencia clínica, Revista Medica del Instituto Mexicano del Seguro Social, 43, $87-95$.

[9] Larios, M.H., Trejo, M.J.A., Cortés, G.T. (1998) Evaluación de la competencia clínica. Revista Medica del Instituto Mexicano del Seguro Social, 36, 77-82.

[10] Rothman, A. I., Blackmore, D., Cohen, R., Reznic, R. (1996) The consistency and uncertainty in examiners' definitions of pass/fail performance on OSCE stations.
Evaluation \& the Health Professions, 16, 322-332.

[11] Garfias, G.G., Aguilar, M.E., Viniegra, V.L. (1997) Cómo explorar las aptitudes de los médicos residentes de traumatología y ortopedia en traumatismo cráneo encefálico. Revista de la Federacion Argentina de Cardiologia, 35, 233-237.

[12] Carlos, A.H., Miriam, D., Sánchez, I., Pérez, C.P., Norberto, E. (2004) Aptitud clínica durante el internado de pregrado en hospitales generales. Revista de la Federacion Argentina de Cardiologia, 42, 469-476.

[13] Searle, J. (2000) Defining competency-the role of standard setting. Med Educ, 34, 363-366.

[14] Gadner, W., Nutting, P.A., Kelleher, K.J. (1996) Does the family Apgar effectively measure family functioning? Aten Primaria, 17, 338-341.

[15] Sánchez, T.E., Pérez, C.L., Navarro, L.M.E., Kumazagua, I.M., Vázquez-Garibay, E. (1994) Dinámica Familiar: Metodología para su evaluación. American Journal of Disease, 7, 48-52.

[16] Lara, E.A., Carrillo, T.J., Carrasco, M.M. (2005) Nutrición en el Síndrome Metabólico. Annual Review del Colegio de Medicina Interna de México; $1^{\mathrm{a}}$ Edición, México, Editorial Intersistemas.

[17] González, C.A., Sánchez, Z.M., Elizondo, A.S. Malanco, H.L. (2005) Inflamación y resistencia a la insulina, su papel en el desarrollo del síndrome meta-bólico. Annual Review del Colegio de Medicina Interna de México; ${ }^{a}$ Edición, México, Editorial Intersistemas.

[18] Sabido, S.M.C., Viniegra, V.L. (2000) Competencia y desempeño en la evaluación del médico: estudio con pacientes diabéticos en el primer nivel de atención. En: Viniegra VL. La investigación en la educación. Papel de la teoría y de la observación. México, IMSS, $1^{a}$ Edición, pp. 251-270.

[19] Vázquez-Garibay, E., Sánchez, T.E, Navarro, L.M.E., Romero, V.E., Pérez, C.L., Kumazagua, I.M.R. (2003) Instrumento de Medición de la dinámica de la familia nuclear mexicana. Un enfoque cuantitativo. Boletín médico del Hospital Infantil de México, 60, 33-52.

[20] SECRETARIA DE SALUD: Reglamento de la Ley General de Salud en materia de investigación para la salud. (1990) México, D.F. Editorial SSA. http://salud.gob.mx/unidades/cdi/nom/compi/rlgsmis.htl m 